\title{
The Choline Incorporation Pathway: Primary Mechanism for de Novo Lecithin Synthesis in Fetal Primate Lung
}

\author{
MICHAEL F. EPSTEIN(58) AND PHILIP M. FARRELL \\ Pregnancy Research Branch and Neonatal and Pediatric Medicine Branch. National Institute of Child Health and \\ Human Development, and Pediatric Metabolism Branch, National Institute of Arthritis, Metabolism, and Digestive \\ Diseases, National Institutes of Health, Bethesda, Marvland, USA
}

\section{Extract}

The two pathways of de novo lecithin synthesis, choline incorporation (I) and phosphatidylethanolamine methylation (II), were examined in lung slices from rhesus monkey fetuses throughout the last half of gestation. Incorporation rates of pathway-specific radioactive precursors were used as a measure of lecithin production. At all stages of development studied, pathway $I$ incorporated 10-50 times more precursor $\left(\left[{ }^{14} \mathrm{C}\right]\right.$ choline $)$ into lecithin than did pathway II $\left(\left[{ }^{14} \mathrm{C}\right]\right.$ methionine or $\left[{ }^{14} \mathrm{C}\right]$ ethanolamine $)$. In addition, although methylation activity did not change significantly during gestation, choline incorporation showed three distinct phases: (1) a stable, relatively low rate in early gestation, (2) an abrupt, twofold increase at approximately $90 \%$ of term, and (3) a return to lower activity levels in late gestation. This correlates with reports that lung lecithin concentration in fetal primates increases significantly in the last $10 \%$ of gestation.

The lecithin to sphingomyelin $(\mathrm{L} / \mathrm{S})$ ratios measured in amniotic fluid samples obtained at abdominal delivery were compared with pathway activities in lung slices from the same fetuses. Significant correlation was found between the amniotic fluid $L / S$ ratio and pathway I activity $(r=0.77, P<\mathbf{0 . 0 0 1})$; in coritrast, pathway II activity showed no relationship to the amniotic fluid $L / S$ ratio. Thus, the $L / S$ ratio appears to be a reflection of lung lecithin synthesis through the choline pathway.

The conclusion that the choline pathway is the primary route of de novo lecithin synthesis in the nonhuman fetal primate lung is supported by three lines of evidence, $(1)$ the predominance of choline incorporation into lecithin, (2) the late gestational rise in conversion of choline to lecithin, and (3) the correlation between pathway I activity and both lung lecithin concentration and amniotic fluid $L / S$ ratio.

\section{Speculation}

Inadequate production of pulmonary lecithin via choline incorporation plays a primary role in the pathogenesis of respiratory distress syndrome (RDS). Future prenatal therapy to selectively increase pathway I activity in the fetal lung with minimal effects on other developing organs will require the definition of the normal intrauterine stimuli of the surge in lecithin synthesis via choline incorporation occurring at $90 \%$ of term gestation.

The fetal lung undergoes extensive anatomic and histologic differentiation during gestation in preparation for its role as an organ for gas exchange in the neonate (16). To successfully adapt to the air breathing state, the fetal lung must also differentiate biochemically and develop the capacity to produce surface active phospholipids of the alveolar lining layer (surfactant) (13). This layer reduces surface tension at the air-tissue interface, preventing the collapse of alveoli on expiration (18). The consequences of diminished pulmonary surfactant have been apparent since Avery and Mead (9) demonstrated that lung minces from early gestational fetuses and from infants succumbing to RDS were unable to develop the low and variable surface tension characteristic of mature lungs. Without this reduction in surface tension, neonatal lung becomes atalectatic and the clinical picture of RDS ensues. Surfactant deficiency in lung extracts from premature infants with RDS has been confirmed repeatedly $(3,15,42)$, and more recent studies in these infants have established that phospholipid levels are diminished in amniotic fluid before delivery (28) and in their lungs $(2,11,15)$. In addition, data from several animal species early in gestation have substantiated these observations in lungs from normal fetuses $(14,20,30,37)$.

The principal phospholipid component of the alveolar lining layer is lecithin (phosphatidylcholine or 1,2-diacyl-sn-glycero3-phosphoryl choline). It is synthesized de novo in the lung via two mechanisms (Fig. 1): pathway I, choline incorporation; and pathway II, phosphatidylethanolamine (PE) methylation (45). Although pathway I appears to be predominant in adult lung (5, $10,38,44,47)$, it has been hypothesized from studies utilizing indirect methods in the premature primate fetus and neonate that PE methylation accounts for the major portion of lecithin synthesis until late gestation $(85-90 \%$ term) $(27,29)$; thus, pathway II has been considered the fetal pathway by some investigators (26). This controversial hypothesis was evaluated in the present investigation by direct measurement of lecithin production in fetal rhesus monkey lung slices incubated with radioactive precursors specific to the two pathways. The study was designed to $(l)$ determine the relative importance of each pathway of lecithin synthesis in fetal primate lung, (2) examine developmental changes in the activity of each pathway throughout the latter half of gestation and the first days of neonatal life, and (3) compare fetal lung lecithin synthesis with the amniotic fluid $\mathrm{L} / \mathrm{S}$ ratio, an indirect index of lung maturity in human fetuses.

\section{MATERIALS AND METHODS}

\section{ANIMALS}

Twenty-two rhesus monkey (Macaca mulatta) fetuses of accurately timed gestations $( \pm 1$ day) from the primate colony of the National Institutes of Health (term gestation $164 \pm 3$ days) were delivered by hysterotomy under $\mathrm{N}_{2} \mathrm{O}$-halothane- $\mathrm{O}_{2}$ anesthesia between 100 and 161 days of gestation. After the abdomen was opened, a specimen of amniotic fluid, free of blood and meconium, was obtained by needle aspiration. Immediately before delivery, $120 \mathrm{mg}$ pentobarbital was injected into an umbilical vessel to kill the fetus, and upon delivery the trachea was compressed manually to prevent reflex expansion of the lungs. The thorax was opened, and the lungs were removed and placed in $0.9 \%$ saline at $4^{\circ}$

Four other rhesus monkeys (mean gestational age 149 days) were delivered alive by cesarean section, maintained in isolettes at 
Pathway I:

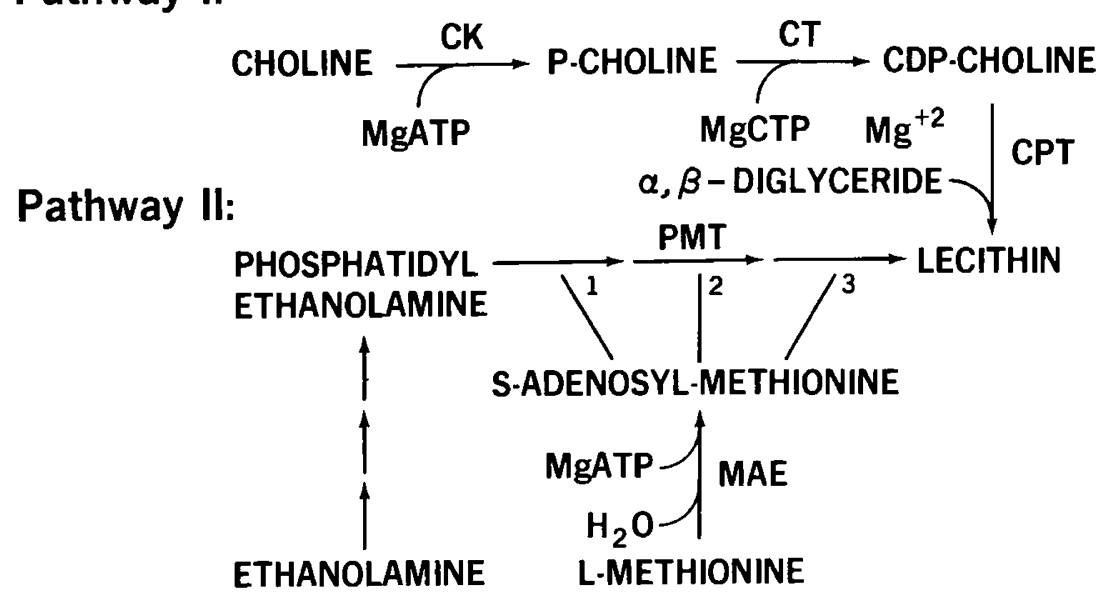

Fig. 1. Pathways of de novo pulmonary lecithin biosynthesis. CK: choline kinase (ATP:choline phosphotransferase, EC 2.7.1.32); CT: cytidyl transferase (CTP:choline phosphate cytidyl choline phosphotransferase, EC 2.7.7.15; CPT: choline phosphotransferase (CDP choline:1,2-diglyceride choline phosphotransferase, EC 2.7.8.2); PMT: phosphatidyl methyl transferase, EC 2.1.1.7); $M A E$ : methionine-activating enzyme; P-choline: phosphorylcholine.

$35-37^{\circ}$, and fed every $4 \mathrm{hr}$ with $10 \%$ dextrose. All remained free of overt respiratory distress and were killed at $24-72 \mathrm{hr}$ of age by intravenous injection of $120 \mathrm{mg}$ pentobarbital. Two young adult rhesus monkeys ( $2-3$ years of age) were killed by exsanguination under ketamine premedication. In all six animals, within 2 min of cessation of respiration, the thorax was opened, and the lungs were handled as above.

\section{IN VITRO INCUBATION}

Within $30 \mathrm{~min}$ of removal from the thorax, the lungs were dissected free of major bronchi and were separated into upper and lower lobes. A Stadie-Riggs microtome was used to prepare slices $(0.5 \mathrm{~mm}$ thickness $)$ from upper and lower lobes of 12 fetuses and from the lower lobes of the remaining fetuses, neonates, and adults. Approximately $250-300 \mathrm{mg}$ tissue ( $2-3$ slices) were placed in individual flasks containing $4 \mathrm{ml} \mathrm{Krebs-Ringer-bicarbonate}$ solution (46), $\mathrm{pH}$ 7.4, which had been equilibrated with $95 \%$ $\mathrm{O}_{2}-5 \% \mathrm{CO}_{2}$. Samples were incubated in duplicate at $37^{\circ}$ under the same gas in a Dubnoff metabolic incubator at a shaking rate of 100 cpm. After a 10 -min preincubation, $2 \mu \mathrm{Ci}$ of the appropriate pathway-specific radioactive precursor were added to each flask. $\left[{ }^{14} \mathrm{C}\right]$ choline $\left(\left[\right.\right.$ meth $\left.y l-{ }^{14} \mathrm{C}\right]$ choline chloride, $\left.60 \mathrm{mCi} / \mathrm{mmol}\right)(53)$ was used to monitor pathway I and $\left[{ }^{14} \mathrm{C}\right]$ methionine ( $\mathrm{L}-[$ methyl${ }^{14} \mathrm{C}$ ]methionine, $\left.46 \mathrm{mCi} / \mathrm{mmol}\right)(54)$ was used to determine pathway II activity.

Lung slices from several fetuses were also incubated with internally labeled $\left[{ }^{14} \mathrm{C}\right]$ choline (choline-[1,2-14 $\left.\mathrm{C}\right]$ chloride, 7.8 $\mathrm{mCi} / \mathrm{mmol}$ ) (54) and $\left[{ }^{14} \mathrm{C}\right]$ ethanolamine (ethanolamine-[1,2${ }^{14} \mathrm{C}$ ]hydrochloride, $\left.78 \mathrm{mCi} / \mathrm{mmol}\right)(54)$ to insure that pathway activities reflect de novo conversion of precursor into product rather than nonspecific utilization of $\left[{ }^{14} \mathrm{C}\right]$ methyl groups. In addition, to prepare $\left[{ }^{14} \mathrm{C}\right]$ lecithin of high specific activity for fatty acid saturation studies, lung slices from one fetus (141 days of gestation) were incubated with $20 \mu \mathrm{Ci}$ of $\left[1,2-{ }^{14} \mathrm{C}\right]$ choline.

Incubation periods of 30-120 min were used to evaluate the changes in radioactive precursor and product levels in lung slices from two fetuses. Based on those results, an incubation period of $60 \mathrm{~min}$ was used to measure pathway activity in the remaining fetal, neonatal, and adult lung slices. At the end of the incubation period, the flasks were rapidly cooled on ice, and the slices were washed extensively with saline at $4^{\circ}$.

\section{LIPID EXTRACTION AND ANALYSIS}

Lipids were extracted by the technique of Folch et al. (25). Twenty volumes of $2: 1$ chloroform-methanol were added to the weighed slices, and the tissue was homogenized thoroughly using a Potter-Elvehjem apparatus. After filtration, an aliquot of 3-5 ml filtrate was mixed vigorously with 0.2 volume of water. Samples were centrifuged at $4,000 \times g$ for $10 \mathrm{~min}$ to provide a two-phase system containing hydrophilic components in the upper, polar phase (UP) and hydrophobic substances in the lower phase (LP). Measurements with isotopic standards demonstrated that excellent separation (less than $1 \%$ spillover of hydrophilic and hydrophobic compounds) was achieved with this technique. An aliquot of UP was counted in $10 \mathrm{ml}$ Aquasol to determine the amount of labeled precursor present in lung tissue $\left({ }^{*}\right.$ Precursor $_{\text {observed }}$ ). In order to identify labeled precursor and intermediates in the UP, an aliquot from one incubation was subjected to cellulose thin layer chromatography (TLC) in propyl acetate-formic acid-water (11:5:3, $\mathrm{v} / \mathrm{v} / \mathrm{v}$ ), a solvent system developed in this laboratory for optimal separation of polar lecithin precursors. Autoradiography was used to identify compounds and to determine label distribution (55).

Aliquots of the lipid-containing LP were spotted on a $250-\mu \mathrm{m}$ TLC plate of silica gel $\mathrm{H}$ for separation in chloroform-methanolwater $(65: 25: 4, v / v / v)$. The lipid spots were visualized by iodination and were scraped into vials containing $10 \mathrm{ml}$ toluene-PPOPOPOP for determination of the amount of precursor incorporated into lecithin $\left({ }^{*} \mathrm{LEC}_{\text {observed }}\right)$ and other lipids.

In order to assess the molecular nature of lecithins synthesized in vitro by choline incorporation, $\left[{ }^{14} \mathrm{C}\right]$ lecithin of high specific activity (about $3 \times 10^{4} \mathrm{dpm} / \mathrm{mg}$ ) was isolated from fetal lung slices (see above) by preparative TLC. The lecithin was then separated by argentation TLC with $5 \% \mathrm{AgNO}_{3}$-impregnated silica gel $\mathrm{H}$. Standard samples of phosphatidyl choline of known fatty acid composition (I, disaturated; II, mono-; III, di-; IV, tetra-; V, hexa-; and VI, octaenoic) (56) were also applied to the plate. Adequate chromatographic separation was achieved with the above solvent system as previously described $(7,56)$. Spots were identified by charring with $50 \% \mathrm{H}_{2} \mathrm{SO}_{4}$, scraped, and counted. Scintillation counting was performed with a Beckman LS-255 instrument which counted at $90 \pm 2 \%$ efficiency for this system as determined by internal standardization.

\section{CALCULATION OF PATHWAY ACTIVITY}

The amount of ${ }^{14} \mathrm{C}$-labeled lecithin produced in lung slices during incubation is determined by the rate of $\left[{ }^{14} \mathrm{C}\right]$ choline incorporation and the rate of PE methylation via $\left[{ }^{14} \mathrm{C}\right]$ methionine, i.e., pathway I and pathway II activity, respectively. Since the radioactivity in lecithin is influenced by variations in the tissue level of isotopic precursor ( ${ }^{*}$ Precursor $_{\text {observed }}$ ), which in turn is 
affected by tissue heterogeneity, individual slice measurements $\left({ }^{*} \mathrm{LEC}_{\text {observed }}\right)$ were adjusted to allow quantitative comparison as follows:

$$
{ }^{*} \text { LEC }_{\text {observed }} \times \frac{{ }^{*} \text { Precursor }_{\text {mean }}}{{ }^{*} \text { Precursor }_{\text {observed }}}={ }^{*} \mathrm{~L} \text { EC cpm } / \mathrm{mg} \text { lung } / \mathrm{hr}
$$

* Precursor mean represents the average lung slice ${ }^{14} \mathrm{C}$-labeled precursor level of all incubations with a given isotope as shown in Table 1.

\section{AMNIOTIC FLUID L/S RATIO}

Amniotic fluid obtained at delivery was cooled immediately at $4^{\circ}$ and centrifuged. The method of Gluck et al. (27), as modified by Olson et al. (39), was utilized to extract the phospholipids from $2-\mathrm{ml}$ aliquots of supernatant by adding 1 volume methanol and 2 volumes chloroform; after vigorous mixing, a two-phase system was established by centrifugation at $2,000 \times g$ for $10 \mathrm{~min}$. After removal of the lower, organic phase, the upper aqueous phase was re-extracted with 2 volumes chloroform. The combined lipid fractions were then concentrated by vacuum rotary evaporation and by evaporation under nitrogen and were chromatographed on silica gel $\mathrm{H}$ as described above. The lipids were visualized by spraying with $50 \% \mathrm{H}_{2} \mathrm{SO}_{4}$ and charring on a hot plate. Measurements of lecithin and sphingomyelin were obtained using a Photovolt-Densicord densitometer and planimeter. Standard curves for lecithin and sphingomyelin were compared and found to be identical in the range of concentrations found in amniotic fluid. $\mathrm{L} / \mathrm{S}$ data represent the ratios of the densities of lecithin and sphingomyelin spots.

\section{DETERMINATION OF ATP}

In two fetuses, samples of fresh lung were removed rapidly and frozen immediately between two pieces of Dry Ice. Lung ATP concentration was measured on such samples and also on lung slices after various periods of the in vitro incubation. This was accomplished by methods similar to those published previously (23) using specific enzymatic analyses after perchloric acid extraction.

\section{RESULTS}

\section{IN VITRO INCUBATION: EXAMINATION OF VARIABLES}

A. Lung ATP Levels. The concentration of ATP in six lower lobe lung samples from two fetuses (141 and 152 days of gestation) was measured at time zero and at 15 -min intervals during a 1 -hr incubation. As shown in Figure 2 this level remained constant with a mean concentration of $1.05 \pm 0.10 \mu \mathrm{mol} / \mathrm{g}$ wet tissue weight (mean $\pm \mathrm{SEM}$ ).

B. Lung Tissue. The effect of anatomic location on pathway activity was determined by comparing choline incorporation in slices from upper and lower lobes of the same fetus. Examination of the two lobes in 12 fetuses (146-161 days of gestation) revealed significantly $(P<0.02)$ greater $\left[{ }^{14} \mathrm{C}\right]$ lecithin formation in upper

Table 1. Level of ${ }^{14} \mathrm{C}$-labeled precursors in lung slices after 60-min incubation

\begin{tabular}{lc}
\hline \multicolumn{1}{c}{ Isotope } & $\begin{array}{r}{ }^{14} \mathrm{C} \text {-labeled precursor level } \\
\mathrm{cpm} / \mathrm{mg} \mathrm{lung} / \mathrm{hr}\end{array}$ \\
\hline$\left[\right.$ methyl- $\left.{ }^{14} \mathrm{C}\right]$ Choline $(22)^{2}$ & $425 \pm 35$ \\
{$\left[1,2-{ }^{14} \mathrm{C}\right] \mathrm{C}$ Choline $(5)$} & $466 \pm 129$ \\
{$\left[\right.$ methyl- $\left.{ }^{14} \mathrm{C}\right]$ Methionine (18) } & $445 \pm 59$ \\
{$\left[1,2-{ }^{14} \mathrm{C}\right]$ Ethanolamine (5) } & $472 \pm 108$
\end{tabular}

\footnotetext{
${ }^{1}$ Mean \pm SEM.

${ }^{2}$ Number of animals is in parentheses.
}

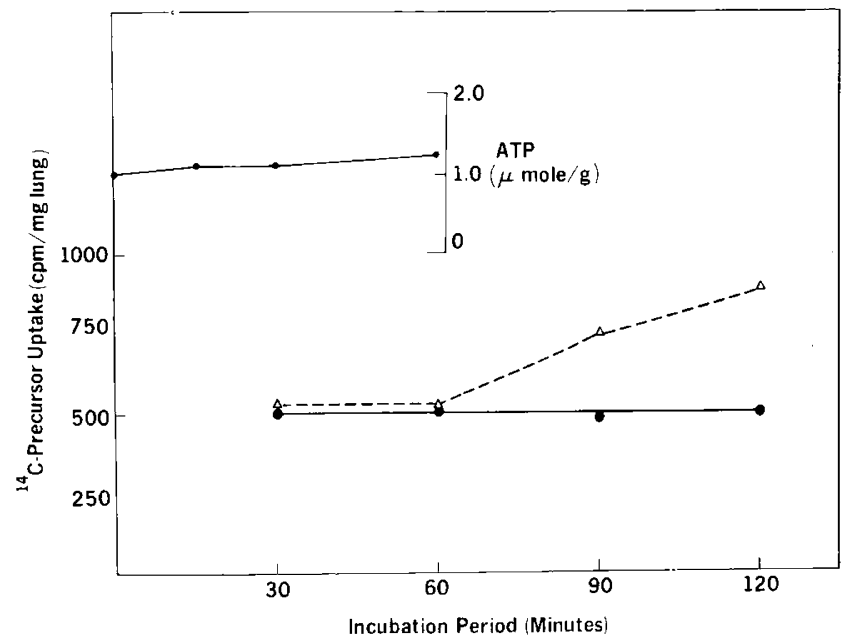

Fig. 2. Level of radioactive precursors and ATP in lung slices as a function of incubation time. Slices utilized were from an 153-day fetus. $\left[{ }^{4} \mathrm{C}\right]$ Choline, $-\left[{ }^{14} \mathrm{C}\right]$ methionine, $\Delta--\Delta$; ATP,

lobes $(1,090 \pm 110 \mathrm{cpm} / \mathrm{mg}$ lung $/ \mathrm{hr}$, mean \pm SEM $)$ as compared with lower lobe slices $(740 \pm 70)$. Lower lobes were used for examination of pathway activity changes with gestation because their larger mass yielded a greater number of uniform slices from a single lobe.

C. Isotopic Precursors. The effect on pathway activity of varying the isotopic preparation was examined by comparing lecithin production from $\left[\right.$ meth $\left.y l-{ }^{14} \mathrm{C}\right]$ choline and $\left[1,2-{ }^{14} \mathrm{C}\right]$ choline for pathway I and $\left[\right.$ methyl- $\left.{ }^{14} \mathrm{C}\right]$ methionine and $\left[1,2-{ }^{14} \mathrm{C}\right]$ ethanolamine for pathway II. Table 1 indicates the levels of ${ }^{14} \mathrm{C}$-labeled precursors in the aqueous phase of lung slice extracts after a 6o-min incubation. All isotopic preparations resulted in equal lung tissue levels of ${ }^{14} \mathrm{C}$-labeled precursors.

$\left[{ }^{14} \mathrm{C}\right]$ Lecithin formation via the two pathways was also independent of the isotopic preparation utilized in the incubation medium. Either $\left[\right.$ methvl $\left.-{ }^{14} \mathrm{C}\right]$ choline or $\left[1,2-{ }^{14} \mathrm{C}\right]$ choline was incubated with lung slices from five fetuses ( 140155 days) in separate flasks. The mean lecithin production via the methyl-labeled choline was not significantly different from that via internally labeled choline, $803 \pm 175 \mathrm{vs} 730 \pm 163 \mathrm{cpm} / \mathrm{mg}$ lung $/ \mathrm{hr}$ (mean \pm SEM). Similarly, when $\left[{ }^{14} \mathrm{C}\right]$ methionine and $\left[{ }^{14} \mathrm{C}\right]$ ethanolamine were used as pathway II precursors, mean lecithin production via methionine was not significantly different from that via ethanolamine, $20 \pm 2$ vs $18 \pm 5, \mathrm{cpm} / \mathrm{mg}$ lung $/ \mathrm{hr}$ (mean $\pm \mathrm{SEM}$ ).

Since both isotopic preparations for each pathway produced comparable tissue precursor levels and incorporation rates, [methyl- ${ }^{14} \mathrm{C}$ ]choline was used to monitor pathway I because of its sevenfold higher specific activity and $\left[\right.$ methyl- $\left.{ }^{14} \mathrm{C}\right]$ methionine was chosen for pathway II because of greater labeling specificity for lecithin than that of ethanolamine (see below, section $E$ ).

D. Incubation Period. The effects of different incubation periods on lung slice ${ }^{14} \mathrm{C}$-labeled precursor levels and $\left[{ }^{14} \mathrm{C}\right]$ lecithin production were examined in two fetuses ( 149 and 153 days of gestation). As shown in Figure 2, $\left[{ }^{14} \mathrm{C}\right]$ choline levels in the lung slices remained constant through $120 \mathrm{~min}$. Although $\left[{ }^{14} \mathrm{C}\right]$ methionine levels remained constant through $60 \mathrm{~min}$, an increase was observed between 60 and $120 \mathrm{~min}$. Therefore, the $60-\mathrm{min}$ steady state incubation period was used for all experiments reported below. Measurement of $\left[{ }^{14} \mathrm{C}\right]$ lecithin formation as a function of incubation period is illustrated in Figure 3. Incorporation rates for both pathway I and II were linear over a period of $120 \mathrm{~min}$.

E. Distribution of ${ }^{14} \mathrm{C}$ in Precursors and Products. The aqueous phase of two lung slice extracts was subjected to cellulose TLC to determine the distribution of ${ }^{14} \mathrm{C}$ in polar compounds. For lung slices incubated with $\left[{ }^{14} \mathrm{C}\right]$ choline, $70 \%$ of precursor radioactivity was present in choline, $29 \%$ in phosphorylcholine, and $1 \%$ in an intermediate compound, CDP-choline. In the case of 
$\left[{ }^{14} \mathrm{C}\right]$ methionine, $64 \%$ of precursor radioactivity remained in the parent compound, the remainder being distributed among various derivatives (e.g., $S$-adenosyl methionine); for $\left[{ }^{14} \mathrm{C}\right]$ ethanolamine, $50 \%$ was found in ethanolamine and the majority of the remaining radioactivity was located in a spot with the mobility of phosphorylethanolamine.

Chromatographic separation of the organic phase of extracts of lung slices incubated with $\left[{ }^{14} \mathrm{C}\right]$ choline demonstrated that $96 \%$ of the incorporated label was present in lecithin. When the precursor was $\left[{ }^{14} \mathrm{C}\right]$ methionine, $65 \%$ of the label was found in lecithin and lysolecithin with the majority of the remaining $35 \%$ found in the fatty acids and neutral lipids moving with the solvent front. In contrast, when $\left[{ }^{14} \mathrm{C}\right]$ ethanolamine was utilized, only $5 \%$ of the lipid incorporated label was present in lecithin, with nearly $80 \%$ appearing in the phosphatidylethanolamine region.

$F$. Choline Incorporation into Saturated and Unsaturated Lecithins. Argentation TLC served to separate $\left[{ }^{14} \mathrm{C}\right]$ lecithins produced in vitro according to the degree of unsaturation. As expected from turnover studies in vivo $(44),\left[{ }^{14} \mathrm{C}\right]$ choline was predominàntly converted to saturated lecithins with the following distribution of labeling: I (disaturated) 60\%, II and III (mono- and

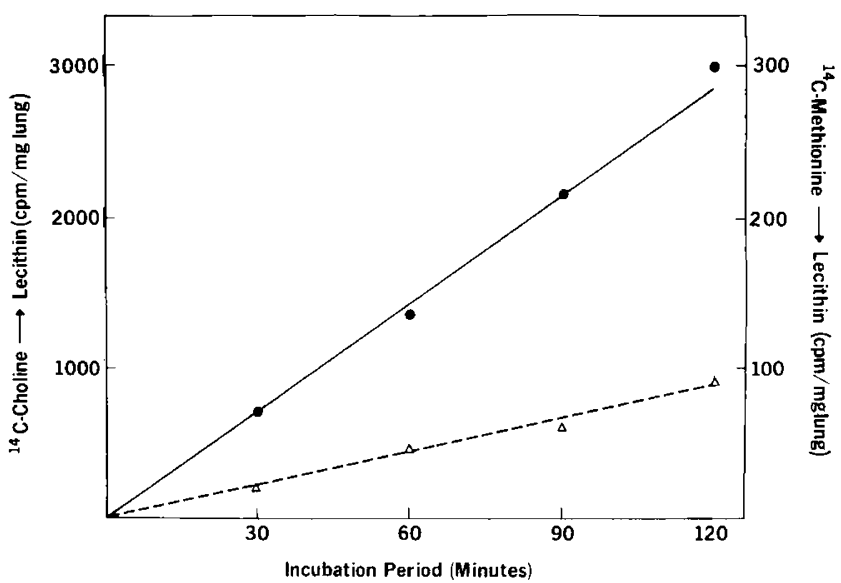

Fig. 3. $\left[{ }^{14} \mathrm{C}\right]$ Lecithin production as a function of incubation time. Lung slices utilized were from an 153 -day fetus. $\left[{ }^{14} \mathrm{C}\right]$ Choline, $\left[{ }^{14} \mathrm{C}\right]$ methionine, $\Delta---\Delta$. dienoic) 4\%, IV (tetraenoic) 30\%, V (hexaenoic) 6\%, VI (octaenoic) $<1 \%$.

\section{CHOLINE INCORPORATION AND PE METHYLATION IN FETUS.} NEONATE, AND ADULT

Figure 4 illustrates pathway I and II activities through the last 64 days of gestation ( 22 fetuses) and the first $72 \mathrm{hr}$ of postnatal life (4 neonates). Pathway I activity was 10-50-fold greater than pathway II activity in each animal throughout this period.

Although pathway II activity shows no significant change with advancing gestational age, there are three distinct phases of pathway I activity in the final half of gestation: ( $l$ ) 100-147 days, early gestation (2) 148-153 days, the transitional or surge period, and (3) 154 days to term, late gestation (Table 2). During the early gestation period, the rate of choline incorporation was $500 \pm 50$ $\mathrm{cpm} / \mathrm{mg}$ lung $/ \mathrm{hr}$ (mean \pm SEM, $n=8$ ). The period of the surge in lecithin synthesis via choline incorporation began at day 148 with an abrupt increase in activity. Peak activity reached by day 150 was nearly threefold higher than that found in the early gestational period. Although activity began to decrease slightly by day 153 , the mean pathway I activity during the entire transitional period $(1,060 \pm 90 \mathrm{cpm} / \mathrm{mg}$ lung $/ \mathrm{hr})$ was significantly $(P<0.001)$ greater than the rate of choline incorporation in early gestation. In the late gestational period pathway I activity declined towards the level seen in early gestation.

Lung slice choline incorporation measured in four neonates appeared to decline approximately $75 \%$ from 24 to $72 \mathrm{hr}$ of postnatal life (Fig. 4). Changes in lecithin synthesis between the first breath and $24 \mathrm{hr}$ were not examined. In two adults, the mean choline incorporation rate was $480 \mathrm{cpm} / \mathrm{mg}$ lung/hr, a rate similar to that of the fetus in early gestation and the neonate $48 \mathrm{hr}$ after delivery.

The level of methylation activity in lung slices of fetuses and neonates was low $(12-74 \mathrm{cpm} / \mathrm{mg}$ lung/hr), and no significant changes in this pathway were apparent through the latter half of gestation and in the early neonatal period. PE methylation in the adult $(14 \mathrm{cpm} / \mathrm{mg}$ lung $/ \mathrm{hr}$ ) was not significantly different from the pathway II activity found in the fetus and neonate.

\section{AMNIOTIC FLUID L/S RATIO}

Figure 5 illustrates amniotic fluid L/S ratios between 130 and 161 days of gestation. Except for the suggestion of a decrease at

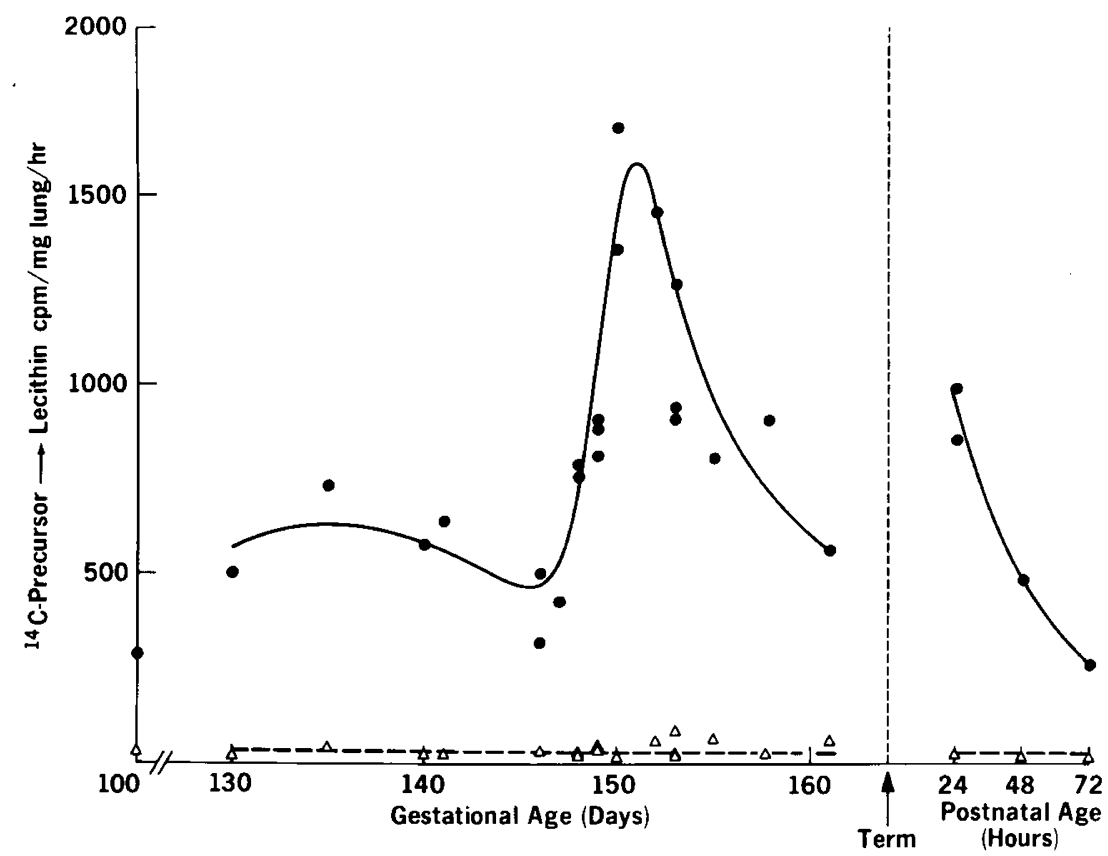

Fig. 4. Pathway activities as related to gestational and postnatal age. Each point represents the average of duplicate lung slice incubations from the lung of a single fetus. Results from 22 fetuses and 4 neonates are shown. $\left[{ }^{14} \mathrm{C}\right] \mathrm{Choline}$, 
146-147 days, the $\mathrm{L} / \mathrm{S}$ ratio increased with advancing gestational age with a particularly rapid rise noted between 148 and 153 days. As shown in Table 2 there was a significant $(P<0.01)$ increase in the $\mathrm{L} / \mathrm{S}$ ratios observed in gestations after the surge in lung choline incorporation into lecithin, i.e., after 148 days: L/S at 130-147 days $=1.0 \pm 0.2($ mean \pm SEM $)$, at $148-161$ days, $2.1 \pm 0.7$.

Figure $6 a$ compares the $\mathrm{L} / \mathrm{S}$ ratio in amniotic fluid from 19 fetuses (130-161 days) with the rate of choline incorporation in lung slices from the same animals. There is a significant correlation $(r=0.77 ; P<0.001)$. In contrast, methylation activity in lung slices from the same animals shows no relationship to the amniotic fluid $\mathrm{L} / \mathrm{S}$ ratio (Fig. $6 b$ ).

\section{DISCUSSION}

The two pathways responsible for de novo lecithin biosynthesi were originally identified in liver and are presented in Figure 1. In the choline incorporation pathway (I), described by Kennedy and Weiss (33), choline is phosphorylated and then "activated" by

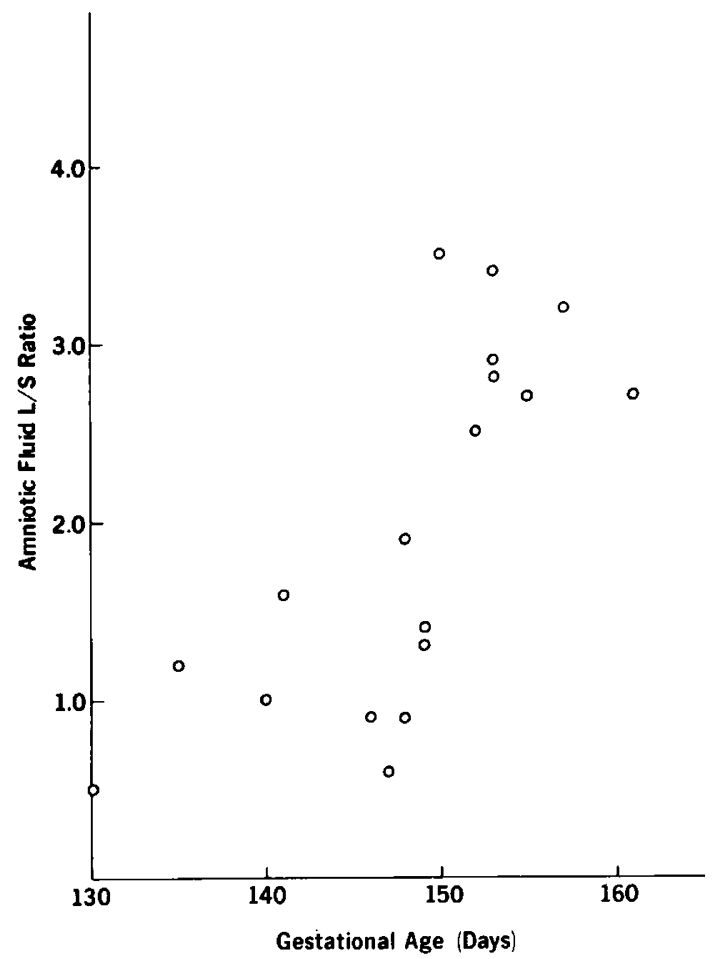

Fig. 5. Amniotic fluid $\mathrm{L} / \mathrm{S}$ ratio as related to gestational age. Fluid was obtained at abdominal delivery of 19 fetuses from 130 to 161 days of gestation. conversion to the CDP-choline derivative. Finally, the phosphorylcholine moiety is transferred to a diglyceride (1,2-diacyl-snglycerol) molecule to form phosphatidylcholine or lecithin. In pathway 1I, described by Bremer and Greenberg (12), ethanolamine undergoes similar steps of phosphorylation, activation, and linkage to diglyceride to form phosphatidylethanolamine; PE then undergoes three successive methylations, with $S$-adenosyl methionine serving as the methyl donor, to form lecithin.

Lung tissue has been shown to possess the enzymes of each pathway for lecithin synthesis in all adult and fetal species examined to date, including human $(49-51)$, monkey $(20,52)$, and rat $(6,24)$. Isotopic studies in rats $(5,44,47)$, rabbits $(38)$, and monkeys (38), have identified the choline pathway as the predominant de novo route in the adult. Investigations in the fetus, however, have not led to the same cross-species agreement. Although data from fetal rats (47) and rabbits $(1,20,30,43)$ confirm the predominance of pathway $I$, results from fetal and neonatal primate studies done by Gluck et al. $(27,29)$ have led to the hypothesis that PE methylation is the major pathway of lecithin synthesis until late in gestation (85-90\% term). Gluck's proposal was based on the indirect method of fatty acid compositional analyses of lecithins from amniotic, tracheal, and pharyngeal fluid of human fetuses and neonates. In contrast, pathway activities were examined in this study by the direct method of measuring the incorporation of labeled precursors into lecithin with lung slices from the rhesus monkey fetus.

Reports from several laboratories have indicated that the rhesus monkey fetus closely resembles the human fetus in terms of organ biochemistry and patterns of development (35). In particular, similarities have been noted with respect to $(l)$ lung phospholipids (34), (2) fatty acid composition of lung and amniotic fluid lecithin $(27,34)$, and (3) amniotic fluid L/S ratios (27). In addition, clinical symptoms and pathologic changes similar to RDS have been observed in rhesus monkey neonates after preterm abdominal delivery and perinatal asphyxia (4). Thus, the fetal rhesus lung provides a useful model of the developing human lung.

The lung slice technique utilized in this study has proven useful in our previous investigations of pulmonary lecithin synthesis in vitro $(22,24)$. The isotope preparations and the length of incubation have been selected to obtain a reproducible steady state system which would be most specific for lecithin synthesis via each pathway. This method does not measure absolute synthetic rates since precursor pool specific activities have not been determined in lung parenchyma. However, it is unlikely that the relative pathway activities were affected by large differences in precursor pool specific activities since: $(l)$ uptake of the three isotopes by lung slices was similar and (2) our estimates of lung methionine and ethanolamine on an amino acid analyzer revealed levels comparable to the concentration of phosphoryl choline in rat lung (47). In addition, it is improbable that there are abrupt changes in the choline and methionine pools during late gestation.

Several lines of evidence suggest that lung slices are viable and

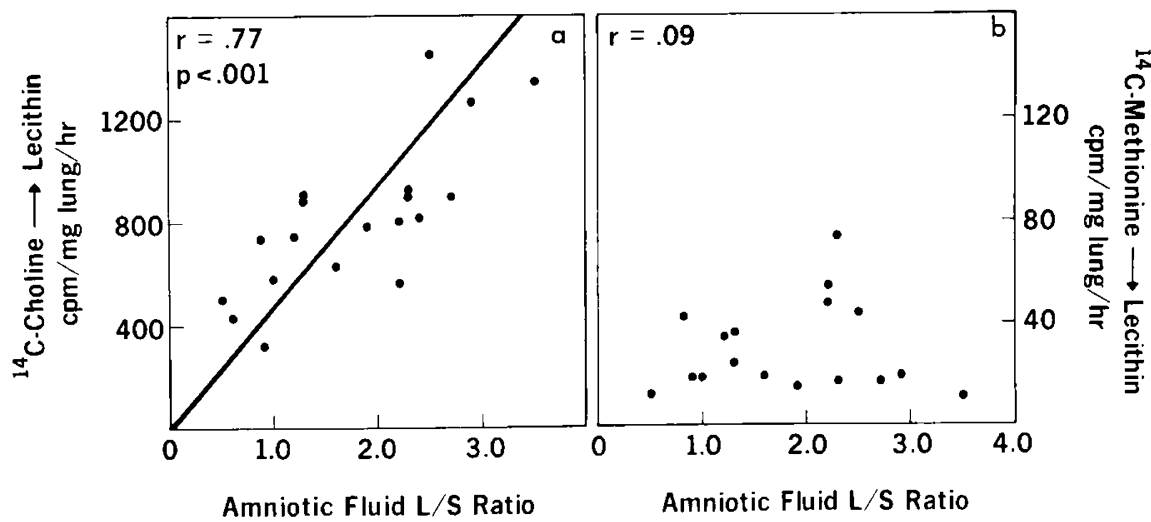

Fig. 6. $a$ : lung slice $\left[{ }^{14} \mathrm{C}\right]$ choline incorporation and amniotic fluid $\mathrm{L} / \mathrm{S}$ ratio. Each point represents a single fetus. $b$ : lung slice phosphatidylethanolamine methylation via $\left[{ }^{14} \mathrm{C}\right]$ methionine and amniotic fluid $\mathrm{L} / \mathrm{S}$ ratio. Each point represents results from a single fetus. 
stable during 2-hr incubations in Krebs-Ringer-bicarbonate: (1) $\left[{ }^{14} \mathrm{C}\right]$ inulin extracellular space and tissue potassium levels are maintained (47), (2) glucose utilization by slices is similar to that of isolated-perfused lung (40), and (3) as reported herein, choline phosphoglyceride production is linear with time. However, since liver slice ATP content has been found to decrease during incubation (36) and since lecithin synthesis by both pathways requires considerable input of high energy phosphate (20), lung ATP was measured during the routine 60 -min incubation. Maintenance of relatively high ATP levels over this period (Fig. 2), in the range reported by others (32), provides further evidence that lung slices are metabolically stable in oxygenated Krebs-Ringer-bicarbonate solution. In addition, the importance of maintaining high levels of ATP in lung slices was demonstrated by another experiment in which slices were incubated in the presence of 0.5 $\mathrm{mM}$ 2,4-dinitrophenol, a compound which lowers energy production by uncoupling mitochondrial oxidative phosphorylation. Inclusion of 2,4-dinitrophenol resulted in a $94 \%$ reduction in choline incorporation into lecithin.

Anatomic variation in pathway activity was noted between upper and lower lobes. This suggests a biochemical basis for the findings of Howatt et al. (3i) and Brumley et al. (14), who noted that upper lobes mature (i.e., have lower surface tension and greater compliance) before lower lobes in fetal lamb lung. Moreover, it stresses the importance of uniformity in tissue sampling for examination of lung phospholipid metabolism.

Results of precursor incorporation measurements (Fig. 4, Table 2 ) indicate that choline incorporation is the predominant pathway of lecithin synthesis throughout the latter half of gestation in the rhesus monkey, even before the late gestational surge in lecithin synthesis. The activity of pathway II was significantly $(P<0.001)$ less than the incorporation rate of $\left[{ }^{14} \mathrm{C}\right]$ choline at all stages of development. Furthermore, choline incorporation greatly exceeded PE methylation in newborn and aduit monkeys. This predominance of pathway I has recently been confirmed in our laboratory by an in vivo study in which $\left[{ }^{3} \mathrm{H}\right]$ choline and $\left[{ }^{14} \mathrm{C}\right]$ ethanolamine were simultaneously injected into fetal rhesus monkeys in utero and incorporation into lung lecithin measured (21). Therefore, we conclude that pathway $\mathrm{I}$ is the major mechanism of lung lecithin synthesis in monkey fetuses.

Changes in pathway activity with advancing gestational age provide further evidence for this conclusion. At 148 days gestation ( $90 \%$ of term), there is an abrupt increase in choline incorporation into lecithin with a twofold increase in pathway I activity within several days. This period of the surge in choline incorporation closely parallels the time of the rise in total and surface-active lung lecithin in fetal monkey lung reported by Kerr and Helmuth (34) and by Morgan and Morgan (37). In addition, the abrupt increase in pathway I activity at $90 \%$ of term gestation has been observed in lungs of other species $(17,47)$. The minor role of PE methylation in lung lecithin synthesis is emphasized by the absence of change in its low level of activity during this transitional phase.

It is of further interest to note that comparable choline incorporation rates were observed in this study in the lungs of early gestational fetuses, neonates after $48 \mathrm{hr}$ of age, and adult monkeys. This rate presumably represents the pathway I activity necessary to provide lecithin for the alveolar surface in a basal state. The doubling of this rate seen between 148 anc 153 days of gestation might be explained teleologically on the basis of the "reservoir theory" proposed by Brumley et al. (15), Platzker et al. (41), Avery (8) and others. This theory states that the fetus must establish high lung lecithin levels before delivery in order to withstand the potential physical (e.g., hypothermia) and biochemical (e.g., acidosis) stresses of the immediate postnatal period which could result in a transient decrease in lecithin synthesis (21). In support of the reservoir theory, recent work of Kerr and Helmuth (34) in the fetal rhesus monkey has demonstrated a nearly threefold increase in lung lecithin between 150 days and term, a time at which the fetal lung lecithin level is twice that seen in the adult monkey. Increased pathway I activity in fetal lung after 148 days, as reported herein, may account for the establishment of this reservoir. Successful achievement of this lecithin reservoir may also be responsible for the decrease in pathway I activity seen in late gestation, the 5-10 days before term.

In addition to these studies of fetal lung lecithin synthesis, amniotic fluid $\mathrm{L} / \mathrm{S}$ ratios were measured during the latter part of gestation in the rhesus monkey. Although some investigators have questioned the contribution of fetal lung to amniotic fluid phospholipids (19), the amniotic fluid $\mathrm{L} / \mathrm{S}$ ratio is firmly established in clinical practice as an indirect measure of fetal lung maturity in the human (48). Measurements of amniotic fluid $\mathrm{L} / \mathrm{S}$ ratio in monkeys have been reported by Gluck et al. (27) and have been carried out in our laboratory on samples reported herein and from 50 additional rhesus gestations. These studies indicate that there is an abrupt increase in the amniotic fluid $\mathrm{L} / \mathrm{S}$ ratio beginning at 148 - 150 days (or $90 \%$ of term gestation). This is comparable to 36 weeks in human gestation, the time of the increase in $\mathrm{L} / \mathrm{S}$ ratio described by Gluck (28). The rise in L/S ratio in the monkey occurs nearly simultaneously with the increase in pathway I activity in fetal lung as reported herein. Furthermore, as demonstrated in Figure $6 a$, there is a significant correlation between the choline incorporation rate of fetal lung slices and the $\mathrm{L} / \mathrm{S}$ ratio of amniotic fluid obtained from the same fetus. This correlation supports the contention of many investigators that fetal lung is the source of changes in amniotic fluid phospholipid composition. Moreover, in view of the reported reduction of lung lecithin in RDS and the clinical value of amniotic fluid $L / S$ ratios in predicting RDS, it suggests that choline incorporation activity is a primary factor in this disorder.

Although no attempt has been made in this study to correlate lung lecithin synthesis or the amniotic fluid $\mathrm{L} / \mathrm{S}$ ratio with the clinical correlate of human RDS in the neonatal monkey, it is of interest to speculate on the implications of our findings in the monkey for interpretation of the $\mathrm{L} / \mathrm{S}$ ratio in the human. An attempt to establish a quantitative relationship between the amniotic fluid $\mathrm{L} / \mathrm{S}$ ratio and pathway I activity during rhesus

Table 2. Pathways $I$ and $I I$ and amniotic fluid $L / S$ ratio as related to gestational and postnatal age ${ }^{1}$

\begin{tabular}{|c|c|c|c|c|}
\hline & $\begin{array}{l}\text { Pathway I, } \\
\mathrm{cpm} / \mathrm{mg} \text { lung/hr }\end{array}$ & $\begin{array}{l}\text { Pathway II, } \\
\mathrm{cpm} / \mathrm{mg} \text { lung/hr }\end{array}$ & $P$ value, I vs II & Amniotic fluid, L/S ratio \\
\hline \multicolumn{5}{|c|}{ Fetuses, gestational age } \\
\hline $100-147$ days & $500 \pm 50(8)$ & $21 \pm 3(8)$ & $<0.001$ & $1.0 \pm 0.2$ \\
\hline $148-153$ days & $1,060 \pm 90^{2}(11)$ & $29 \pm 7(9)$ & $<0.001$ & $2.1 \pm 0.3^{3}$ \\
\hline 154-16i days & $750 \pm 100(3)$ & $40 \pm 12(3)$ & $<0.001$ & $2.4 \pm 0.2^{3}$ \\
\hline \multicolumn{5}{|l|}{ Neonates } \\
\hline $24-72 \mathrm{hr}$ & $650 \pm 70(4)$ & $12 \pm 3(3)$ & $<0.001$ & \\
\hline Adults & 480 & $14 \quad$ (2) & & \\
\hline
\end{tabular}

${ }^{1}$ All values represent mean \pm sem; number of animals is in parentheses.

2 Pathway I activity at $148-153$ differs from $100-147$ at $P<0.001$.

${ }^{3}$ Amniotic fluid L/S at $148-153$ and at $154-161$ differs from $100-147$ at $P<0.01$. 
monkey gestation is presented in Figure 7 . The quadrants of this graph were established on the basis of (I) 148 days of gestational age, the onset of the transition from a low to a high rate of choline incorporation into lecithin and (2) the choline incorporation rate of $750 \mathrm{cpm} / \mathrm{mg}$ lung $/ \mathrm{hr}$, the $90 \%$ confidence limit of mean pathway I activity during early gestation (100-147 days). All six fetuses younger than 147 days had pathway I activities below $750 \mathrm{cpm} / \mathrm{mg}$ lung/hr. In contrast, 12 of the 13 fetuses older than 147 days had pathway I activities greater than this level. The one exception, the fetus nearest term, might be explicable on the basis of the lecithin reservoir having already been established, resulting in a return of the choline incorporation rate to earlier levels. It is probable that at levels of choline incorporation greater than $750 \mathrm{cpm} / \mathrm{mg}$ lung/hr (in this in vitro system) the lung has matured in its ability to synthesize lecithin.

The amniotic fluid $\mathrm{L} / \mathrm{S}$ ratio which is comparable to this pathway activity is 1.5 as determined from Figure $6 a$. When fetuses in the group 148 days to term were examined, 10 of the 13 had an $\mathrm{L} / \mathrm{S}$ ratio greater than 1.5 . The remaining three were at 148 or 149 days, the first 2 days of the transitional period, suggesting that there is a lag of $24-48 \mathrm{hr}$ between the onset of changes in the lung and their adequate reflection in the amniotic fluid. This may provide an explanation for the large number of human neonates born with an amniotic fluid $\mathrm{L} / \mathrm{S}$ ratio of less than 2.0 who do not develop RDS. In the group of fetuses less than 148 days of gestation, five of six $\mathrm{L} / \mathrm{S}$ ratios were below 1.5 and one fetus at 135 days had an $\mathrm{L} / \mathrm{S}$ ratio of 1.6. Therefore, in the rhesus monkey, as in the human (26), an L/S ratio of 1.5-2.0 might best be viewed as transitional.

On the basis of these findings in the nonhuman primate, it appears that the current use of the amniotic fluid L/S ratio to predict pulmonary maturity in the human fetus is based on developmental changes in lung choline incorporation into lecithin.

\section{SUMMARY}

Lung lecithin synthesis has been measured directly in vitro by determining the incorporation of pathway specific radioactive precursors $\left[{ }^{14} \mathrm{C}\right]$ choline and $\left[{ }^{14} \mathrm{C}\right]$ methionine. Findings indicate

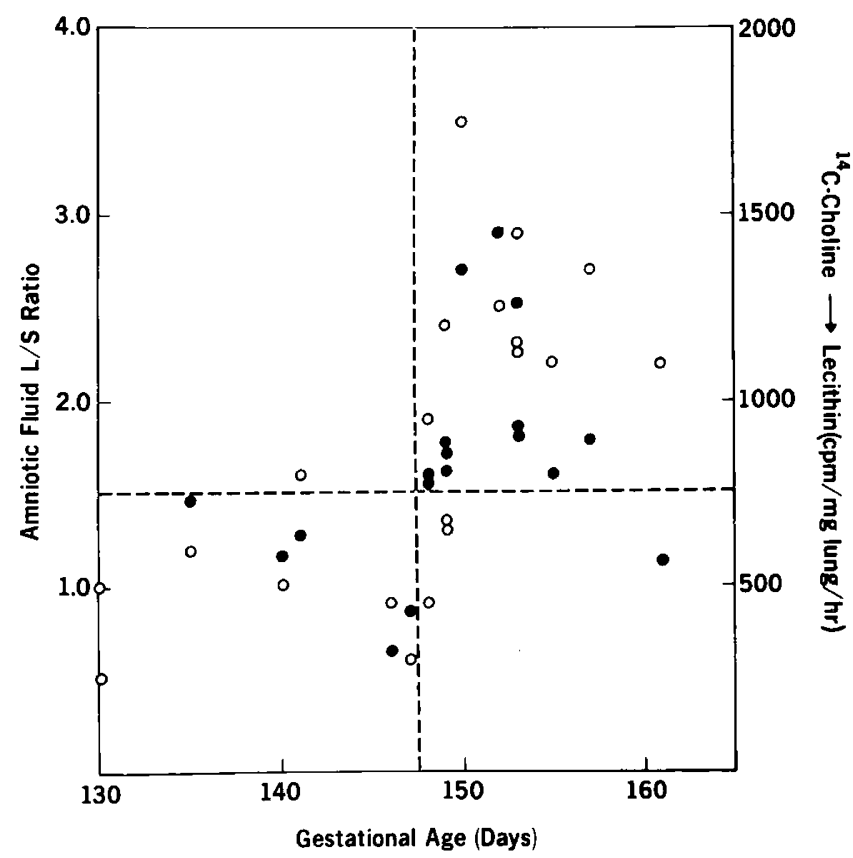

Fig. 7. Lung slice $\left[{ }^{14} \mathrm{C}\right]$ choline incorporation into lecithin $(-)$ and amniotic fluid $\mathrm{L} / \mathrm{S}$ ratio $(\mathrm{O})$ as a function of gestational age. Horizontal dashed line: pathway I activity of $750 \mathrm{cpm} / \mathrm{mg}$ lung/hr, the theoretical lower limit of pulmonary maturity in this lung slice system; vertical dashed line: 147-148 days, the onset of the surge in pulmonary pathway I activity in the monkey fetus. that the choline pathway is the predominant mechanism of de novo lecithin synthesis throughout gestation and accounts for the late gestational surge in lecithin synthesis in the fetal rhesus monkey lung. Pathway I activity in lung was also shown to correlate with the amniotic fluid $\mathrm{L} / \mathrm{S}$ ratio, suggesting that the latter reflects pulmonary production of lecithin through the choline pathway.

\section{ADDENDUM}

In addition to these data on slices from whole lung, radioisotopic analysis of pathway activities in cultured, homogeneous type II pneumocytes in this laboratory has revealed similar predominance of the choline pathway.

\section{REFERENCES AND NOTES}

1. Abe, M., Akino, T., and Ohno, K: On the metabolism of lecithin in lung and liver of fetal rabbits. Tohoku J. Exp. Med., 109: 163 (1973).

2. Adams, F. H., Fujiwara, T., Emmanouilides, G. C., and Raiha, N.: Lung phospholipids of human fetuses and infants with and without hyaline membrane disease. J. Pediat., 77: 833 (1970).

3. Adams, F. H.. Fujiwara, T., Emmanouilides, G. C., and Scudder, A.: Surface properties and lipids from lungs of infants with hyaline membrane disease. J. Pediat., 66: 357 (1965).

4. Adamsons, K. Behrman, R., Dawes, G. S., James, L. S., and Koford, C.: Resuscitation by positive pressure ventilation and Tris-hydroxymethylaminomethane of rhesus monkeys asphyxiated at birth. J. Pediat., 65: 807 (1964).

5. Akino, T., Abe, M., and Arai, T: Studies on the biosynthetic pathways of molecular species of lecithin by rat lung slices. Biochim. Biophys. Acta, 248: $274,(1971)$

6. Artom, C.: Enzymes for the synthesis of lecithins from choline in tissue of developing rats. Fed. Proc., 27: 457 (1968).

7. Arvidson, G. E.: Structural and metabolic heterogeneity of rat liver glycerophosphatides. Eur. J. Biochem., 4: 478 (1968)

8. Avery, M. E.: The pulmonary surfactant in foetal and neonatal lungs. In: Foetal and Neonatal Physiology (Cambridge University Press, Cambridge, 1973).

9. Avery, M. E., and Mead. J.: Surface properties in relation to atelectasis and hyaline membrane disease. Amer. J. Dis. Child., 97: 517 (1959).

10. Bjornsted, P., and Bremer, J.: In vivo studies on pathways for the biosynthesis of lecithin in the rat. J. Lipid. Res., 7: 38 (1966).

11. Boughton, K., Gandy, G., and Gardner, D.: Hyaline membrane disease. 1I. Lung lecithin. Arch. Dis. Childhood, 45: 311 (1970).

12. Bremer, J., and Greenberg, D. M.: Methyl-transferring enzyme system of microsomes in the biosynthesis of lecithin (phosphatidylcholine). Biochim. Biophys. Acta, 46: 205 (1961).

13. Brumley, G. W.: Lung development and lecithin metabolism. Arch. Intern. Med. 127: $413(1971)$.

14. Brumley, G. W. Chernick, V., Hodson, W. A.. Normand, C., Fenner, A., and Avery, M. E.: Correlations of mechanical stability, morphology, pulmonary surfactant, and phospholipid content in the developing lamb lung. J. Clin. Invest., 46: 863 (1967).

15. Brumley, G. W., Hodson, W. A., and Avery, M. E.: Lung phospholipids and surface tension correlations in infants with and without hyaline membrane disease and in adults. Pediatrics, 40:13 (1967).

16. Charnock, E. L., and Doershuk, C. F.: Developmental aspects of the human lung. Pediat. Clin. N. Amer., 20: 275 (1973).

17. Chida, N and Adams, F. H.: Incorporation of palmitate, glucose, and choline into lecithin by fetal and newborn lamb lung. Pediatrics, $l: 364$ (1967).

18. Clements, J. A.: Surface tension of lung extracts. Proc. Soc. Exp. Biol. Med., 95. $170(1957)$.

19. Condorelli, S., Cosmi, E., and Scarpelli, E. M.: Extrapulmonary source of amniotic fluid phospholipids. Amer. J. Obstet. Gynecol., 118: 842 (1974).

20. Farrell, P. M.: Regulation of pulmonary lecithin synthesis. In: C. A. Villee, D. B. Villee and J. Zuckerman: Respiratory Distress Syndrome (Academic Press, New York, 1973).

21. Farrell, P. M., Epstein, M. F., Fleischman, A. R., Oakes, G. K., and Knight, E.: Lecithin synthesis in fetal primate tissues as measured in vivo. Pediat. Res., 8: 446 (1974).

22. Farrell, P. M., Lundgren, D. W., and Adams, A. J.: Choline kinase and choline phosphotransferase in developing fetal rat lung. Biochem. Biophys. Res. Commun., 57: 696 (1974)

23. Farrell, P. M., and Olson, R. E.: Creatine phosphate and adenine nucleotides in muscle from animals with muscular dystrophy. Amer. J. Physiol., 225: 1102 (1973).

24. Farrell, P. M., and Zachman, R. D.: Induction of choline phosphotransferase and lecithin synthesis in the fetal lung by corticosteroids. Science, 179: 297 (1973).

25. Folch, I., Lees, M., and Stanley, G. H. S.: A simple method for the isolation and purification of total lipids from animal tissues. J. Biol. Chem., 226: 497 (1957).

26. Gluck, L.: Surfactant: 1972. Pediat. Clin. N. Amer., 19: 325 (1972).

27. Gluck, L., Chez, R. A., Kulovich, M., Hutchinson, D. L., and Niemann, W. H.: Comparison of phospholipid indicators of fetal lung maturity in amniotic fluid of monkey (Macaca mulatta) and baboon (Papio papio). Amer. J. Obstet. Gynecol., 120: 524 (1974). 
28. Gluck, L.. Kulovich, M. V., Borer, R. C., Brenner, P. H., Anderson, G. G., and Spellacy, W. N.: Diagnosis of the respiratory distress syndrome by amniocentesis. Amer. J. Obstet. Gynecol., 109: 440 (1971).

29. Gluck, L., Kulovich, M. V., Eidelman, A. 1., Cordero, L., and Khatin, A. F Biochemical development of surface activity in mammalian lung IV. Pulmonary lecithin synthesis in the human fetus and newborn and etiology of the respiratory distress syndrome. Pediat. Res.. 6: 81 (1972).

30. Gluck, L., Scribney, M., and Kulovich, M.: The biochemical development of surface activity in mammalian lung II. The biosynthesis of phospholipids in the lung of the developing rabbit fetus and newborn. Pediat. Res., 1: 247 (1967).

31. Howatt, W. F., Avery, M. E., Humphreys, P. W., Normand, I. C. S., Reid, L., and Strang, L. B.: Factors affecting pulmonary surface properties in the foetal lamb. Clin. Sci., 29: 239 (1965).

32. Isselhard, W., Fischer, J. H., Kapune, H., and Stock, W.: Metabolic pattern of several tissues of rabbits and guinea pigs during postnatal development. Biol. Neonate, 22: 201 (1973)

33. Kennedy, E. P., and Weiss, S. B.: The function of cytidine coenzymes in the biosynthesis of phospholipids. J. Biol. Chem., 222: 193 (1956).

34. Kerr, G. R., and Helmuth, A. C.: Growth and development of the fetal rhesus monkey: V. Fatty acids of phospholipids in fetal lung. Biol. Neonate, 25: 10 (1974).

35. Kerr, G. R.. and Waisman, H. A.: Fetal biology of the rhesus monkey. In: Medical Primatology 1970 (Karger, Basel, 1970).

36. Krebs, H. A.: Rate control of the tricarboxylic acid cycle. Advan. Enzyme Regul., 8: 335 (1970).

37. Morgan, T. E., and Morgan, B. C.: Surfactant synthesis, storage, and release by alveolar cells. In: C. A. Villee, D. B. Villee, and J. Zuckerman: Respiratory Distress Syndrome (Academic Press, New York, 1973).

38. Motoyama, E. K., and Rooney, S. A.: Does the methylation pathway contribute to the biosynthesis of surface active phosphatidylcholine in the lung. Fed. Proc., 33: 346 (1974).

39. Olson, E. B., Graven, S. N., and Zachman, R. D.: Amniotic fluid lecithin/sphin gomyelin $(\mathrm{L} / \mathrm{S})$ ratio of 3.5 and fetal pulmonary maturity. Pediat. Res., 9: 65 (1975).

40. O'Neill, J. J., and Tierney, D. F.: Rat lung metabolism: glucose utilization by isolated perfused lungs and tissue slices. Amer. J. Physiol., 226: 867 (1974).

41. Platzker, A., Clements, J., and Tooley, W.: Surfactant development in the human fetal lungs. Clin. Res., 19: 232 (1974).

42. Reynolds, E. O. R., Orzalesi, M. M., Motoyama, E. K., Craig. J. M., and Cook, C. D.: Surface properties of saline extracts from lungs of newborn infants. Acta Paediat. Scand., 54: 5 HI (1965).

43. Russell, B. J., Nugent, L., and Chernick, V.: Effects of steroids on the enzymatic pathways of lecithin production in fetal rabbits. Biol. Neonate, 24: 306 (1974).

Copyright @ 1975 International Pediatric Research Foundation, Inc.
44. Spitzer, H. L., Morrison. K., and Norman, J. R.: The incorporation of $\mathrm{L}-\left(\mathrm{Me}-{ }^{14} \mathrm{C}\right)$-Methionine and $\left(\mathrm{Me}^{-3} \mathrm{H}\right)$-Choline into lung phosphatides. Biochim. Biophys. Acta, 152: 552 (1968).

45. Thompson, G. A. Phospholipid metabolism in animal tissues. In: G. B. Ansell, J. N. Hawthorne, and R. M. C. Dawson: Form and Function of Phospholipids, Chap. 4 (Elsevier Scientific, Amsterdam, 1973).

46. Umbreit, W. W., Burris, R. H., and Stauffer, J. F.: Manometric and Biochemical Techniques (Burgess, Minneapolis, 1972)

47. Weinhold, P.: Biosynthesis of phosphatidyl choline during prenatal development of the rat lung. J. Lipid. Res., 9: 262 (1968).

48. Whitfield, C. R.: The diagnostic value of amniocentesis. Clin. Obstet. Gynecol., 1: 67 (1974).

49. Zachman, R. D.: The enzymes of lecithin biosynthesis in human newborn lungs $I$. Choline Kinase. Biol. Neonate, 19: 211 (1971).

50. Zachman, R. D.: The enzymes of lecithin biosynthesis in human newborn lungs II. Methionine-activating enzyme and phosphatidyl methyltransferase. Biol. Neonate, 20: 448 (1972)

51. Zachman, R. D.: The enzymes of lecithin biosynthesis in human newborn lungs III. Phosphorylcholine glyceride transferase. Pediat. Res., 7: 632 (1973).

52. Zachman, R. D., and Chung. A.: Personal communication.

53. Amersham-Searle, Arlington Heights. III.

54. New England Nuclear, Boston, Mass

55. Kodak NS medical x-ray film

56. The following phosphatidylcholines (PC), synthesized to $>99 \%$ purity, were obtained from Applied Science Laboratories, Inc., State College, Pa.: I (disaturated), dipalmitoyl and distearoyl PC; II (monoenoic), I-palmitoyl, 2-palmitoleoyl PC and I-stearoyl, 2-oleoyl PC; III (dienoic), dioleoyl PC: IV (tetranenoic), dilinoleoyl PC: V (hexaneoic), dilinolineoyl PC; VI (octoenoic), diarachidonyl PC. When chromatographed on the argentation thin laye chromatography system described, these compounds migrated as follows (median distance relative to solvent front): I, 0.36; II, 0.34; III, 0.32; IV, 0.27 V, $0.12 ;$ VI, 0.10

57. The authors are grateful to Dr. Ronald A. Chez, Chief, Pregnancy Research Branch, NICHD, for his surgical expertise and his valuable support and suggestions in the preparation of this manuscript. The continued interest and encouragement of Dr. Paul A. di Sant'Agnese, Chief, Pediatric Metabolism Branch, NIAMDD, and the assistance of Dr. Alan Fleischman, Dr. Gary Oakes, Elizabeth Knight, Jane Willison, Anthony Adams, and Agnes Chung Loh are also appreciated.

58. Requests for reprints should be addressed to: M. F. Epstein, M.D., Children's Service, Massachusetts General Hospital, Fruit St. Boston, Mass. 02114 (USA).

59. Accepted for publication April 10, 1975 